\title{
Development of a rational practice of therapeutics
}

\author{
Michael D Rawlins
}

Wolfson Unit of Clinical

Pharmacology,

Department of

Pharmacological Sciences,

University of Newcastle

upon Tyne, Newcastle

upon Tyne NE1 7RU

Michael D Rawlins, FFPM, professor of clinical

pharmacology

BrMed f 1990;301:729-33
One hundred and fifty years ago most treatments were developed either from a naive (and often erroneous) view of disease processes and aetiologies or from anecdotal observations of the beneficial effects of particular remedies in individual patients. Treatment was thus based on a combination of hypothesis and empiricism.

Professional scepticism and public concern about the state of therapeutics emerged around the turn of the century and underwent its catharsis in 1909. In that year the BMA published, in popular form, an exposé, entitled Secret Remedies, of some of the patent medicines promoted to the public. ${ }^{1}$ At that time the patent medicine trade was bringing personal fortunes to the innovators, appreciable excise duty to the exchequer, and considerable advertising revenues to the popular national and provincial press (with the notable exception of the Spectator). Manufacturers' claims were extravagant, and Beecham's pills (containing only aloes, ginger, and soap) were, for example, promoted for indications that included "maladies of indiscretion, kidney and urinary disorders, and menstrual derangements."'

Despite the fact that many newspapers (including the News of the World) refused to carry advertisements for Secret Remedies its sales exceeded the association's wildest expectations, and to meet public demand it ran to five impressions in three months. A successful sequel entitled More Secret Remedies appeared in 1911, and parliamentary concern lead to the appointment of a select committee to examine patent medicines.

The committee sat during three sessions of parliament and heard evidence from many sources. The witnesses included Sir Joseph Beecham, who underwent a hostile public cross examination. The committee was particularly worried over claims that Sir Joseph's

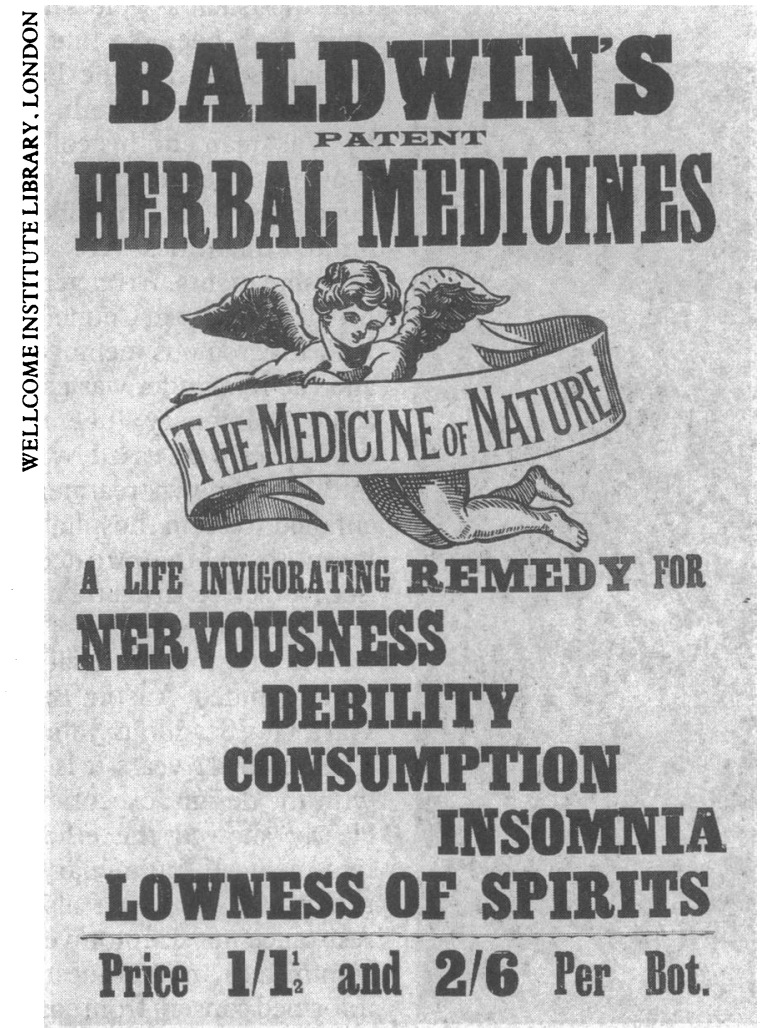

pills were promoted for "maladies of indiscretion." Did this not suggest, members asked, use as an abortifacient? The select committee in its final report advised that measures were required to protect the public against injury and fraud, and it recommended that the promotion and sale of proprietary medicines should be closely regulated by the newly created Ministry of Public Health. ${ }^{3}$ Sadly, the report was published on 4 August 1914 and was thus overshadowed by more pressing world events. Despite this the report presaged the passage of the venereal disease and cancer acts (which forbid promotion to the public of cures for these diseases). Moreover it conditioned both the medical profession and the general public to take a more critical view of the therapeutic claims of medicines. ${ }^{4}$

Since 1914 three concepts have revolutionised the principles and practice of therapeutics. Firstly, orthodox doctors have increasingly come to accept that while hypotheses are a sound basis for therapeutic experiments they are an insecure guide to therapeutic practice. Secondly, doctors have realised that, with singular exceptions, therapeutic anecdote provides a poor basis for clinical practice. Thirdly, and more recently, it has been recognised that no therapeutic manoeuvre is without hazard and that rational treatment entails a trade off between risk and benefit. In this article I review the effects of these three concepts in shaping current therapeutic practices and reflect on future trends.

\section{Flawed hypotheses}

Hypotheses alone are a dangerous basis for determining routine clinical practice because they are so frequently flawed. Phlebotomy was practised for nearly 2000 years for the best of contemporary motives: in Galen's time exsanguination removed evil poisons; by the early nineteenth century bleeding patients with pneumonia to syncope was intended to reverse a dangerously hyperkinetic circulation.

The twentieth century has witnessed comparable foolishness. The observation that gold salts inhibited, in vitro, the growth of Mycobacterium tuberculosis lead to the widespread use of Sanocrysin (sodium aurothiosulphate) as a treatment for tuberculosis during the 1920 s and 1930s. ${ }^{5}$ The rise and decline of radical mastectomy to clear microscopic metastases in the axillary lymph nodes of patients with breast cancer is a postwar example of a similar well intentioned folly in which I have to confess to having been a willing, if inexpert, accomplice when a house surgeon.

In recent years our capacity for incredulity has become more sophisticated. Benoxaprofen (Opren), a non-steroidal anti-inflammatory agent, was introduced in 1980 with the promotional claim (in journals including the $B M \mathcal{Y}$ ) that it "Has been shown, experimentally, to actually modify the arthritic disease process." This claim was based on the observation that benoxaprofen inhibited the development of adjuvant induced arthritis in the rat ${ }^{6}$ but failed to mention that other non-steroidal anti-inflammatory drugs (including naproxen, indomethacin, and ketoprofen) had similar actions or that beneficial effects shown in rats have only a limited ability to predict efficacy in humans. And doctors today who prescribe aspirin at daily doses of $75 \mathrm{mg}$ or less do so on no more than a presumption that the pharmacological actions of low doses of salicylates are 


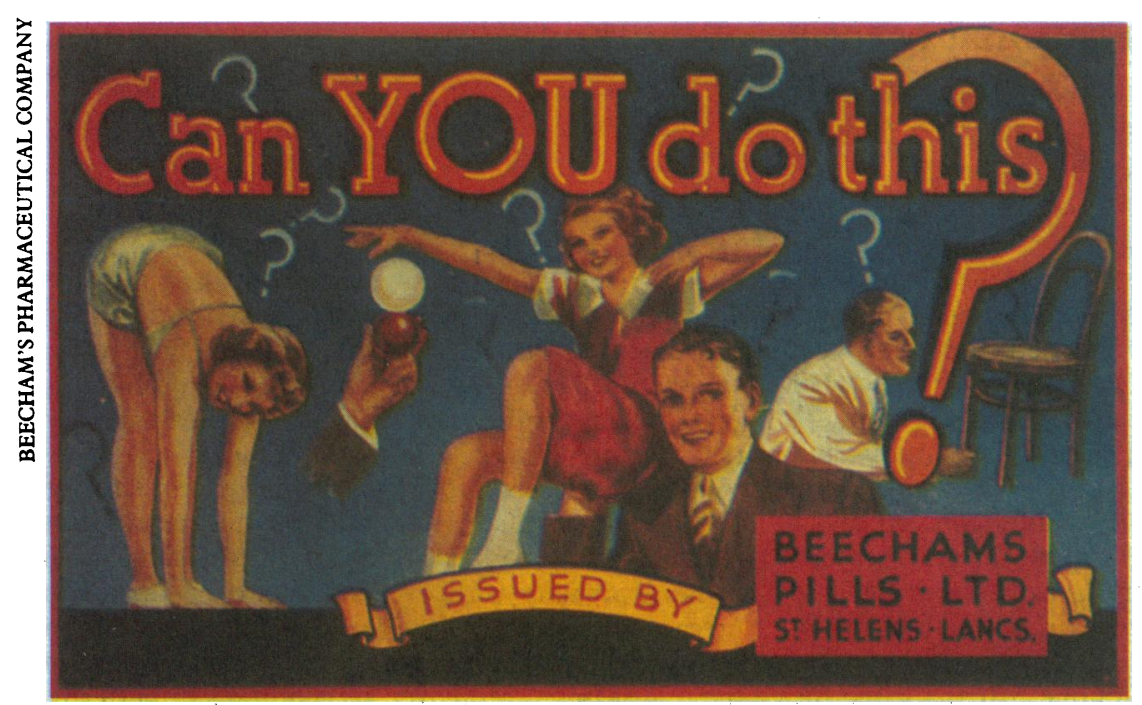

Ambitious claims for Beecham's pills in the late 1920s the same as those producing therapeutic effects at higher doses.

Careful observation has an honourable and established place in advancing medical knowledge. Like therapeutic hypotheses, however, clinical experience is rarely more than a starting point for a formal evaluation of efficacy.

There are a few, rare instances when clinical observations alone have been sufficiently persuasive to show unequivocal benefit. These include the effects of insulin in type I diabetes, liver extracts in pernicious anaemia, neostigmine in myasthenia gravis, and streptomycin in tuberculous meningitis. All of these conditions were characterised by inexorable progression to death and by an unequivocal response to treatment. They have been the exceptions rather than the rule, and the emergence in the twentieth century of rational therapeutics has depended on the development of the randomised controlled trial.

\section{Controlled trials}

The use of controls in experimental science is not a recent innovation. King Nebuchadnezzar reputedly

The risk-benefit ratio for venesection was not favourable used a control group to study the effects of diet, ${ }^{7}$ and during the eighteenth century Lind compared the effects of various treatments (including two oranges and a lemon a day) on the course of scurvy. ${ }^{8}$ In the nineteenth century the use of controls, usually without further description, became established in the vocabulary of biology. ${ }^{9}$ Controlled studies of the effects of treatment, and hence the development of therapeutics as a science, have evolved during the twentieth century.

Early clinical trials suffered from two major defects. Firstly, although some had a crossover design none used randomisation in their allocation of treatments in parallel group studies. In the Lanarkshire milk experiment, for example, the allocation of children to receive supplementary milk was left to head teachers ${ }^{10}$; it subsequently became clear that an excess of ill nourished children had been allocated to receive extra milk. " The second defect lay in the absence of any statistical analyses of the results. Thus in the early 1930s the Medical Research Council's study of serotherapy in patients with lobar pneumonia concluded, without clear evidence to reject the null hypothesis, that while treatment had not reduced mortality in older patients it had done so in younger ones. ${ }^{12}$ Two developments between 1935 and 1950 in clinical trial methodology, however, set the pattern for modern therapeutic research.

\section{Randomisation and the streptomycin trial}

The publication of the results of the Medical Research Council's trial of streptomycin in 1948 showed how a randomised controlled trial that was subjected to critical statistical assessment could (and should) be conducted in patients with a potentially lethal condition to yield results of major scientific importance and practical value. ${ }^{13}$ The fact that the study was ever undertaken was a result of several factors. Firstly, and probably most importantly, a group of young doctors had been impressed by Austin Bradford Hill's advocacy of statistical methods during the 1930s in a series of lectures at the Hammersmith Hospital and articles in the Lancet. ${ }^{14}$ Secondly, younger respiratory doctors were clearly appalled by the way antituberculous remedies such as gold salts and treatment with tuberculin had been so uncritically adopted and then abandoned during the 1920s and 1930s. ${ }^{5}$ Thirdly, in 1946 streptomycin was in short supply. First discovered by Waksman and his colleagues in $1943,{ }^{15}$ it had been shown to be effective in experimental tuberculous infections $^{16}$ and in tuberculous meningitis. ${ }^{17}$ Only limited quantities were available, however, for use in British patients. Arrangements were made through the Medical Research Council for supplies to treat patients with tuberculous meningitis and miliary tuberculosis, and the remainder was used for a trial in patients with acute pulmonary tuberculosis. Finally, the ethical difficulties were eased by the shortage of beds: in 1946 the "best" known treatment for pulmonary tuberculosis entailed rest in hospital, and enrollment therefore meant that both untreated controls and those randomised to active drug treatment benefited from earlier hospital admission.

The streptomycin trial was supervised by a glitterati that included Austin Bradford Hill, Philip D'Arcy Hart, Guy Scadding, John Gaddum, and John Crofton. Even after 42 years it is difficult to find serious fault with the design, execution, or analysis of the study. It clearly showed the efficacy of streptomycin in the treatment of pulmonary tuberculosis in a defined group of patients. It also showed the emergence of resistance to streptomycin. Although today's ethics committees might question the denial of obtaining informed consent from control patients, such a criticism 


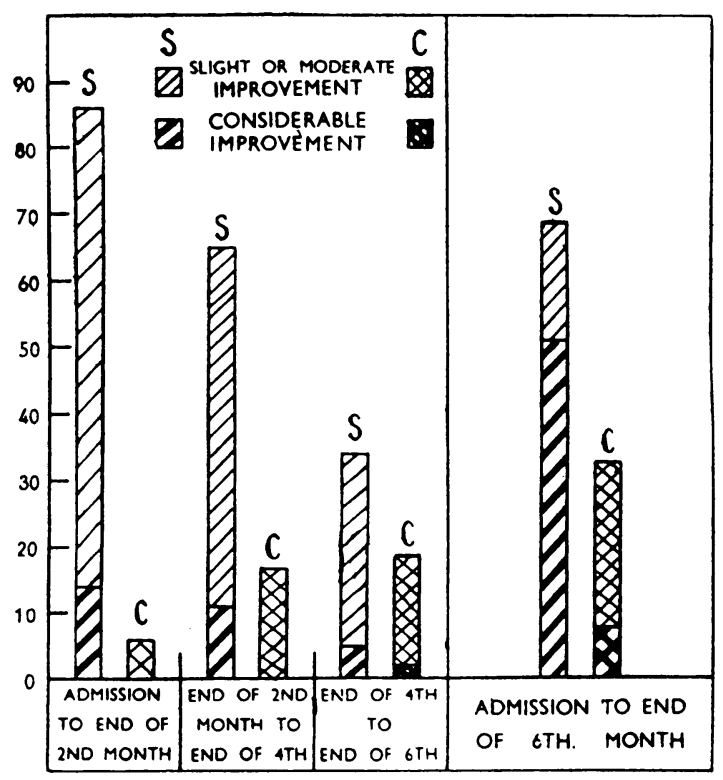

Why the "BMY" doesn't like histograms any more. Comparison of percentage of control patients and patients treated with streptomycin showing improvement on radiology in the 1948 MRC trial of streptomycin

is a commentary on the prevailing mood of the period rather than on the organisers of the study.

The streptomycin study and the antituberculous trials that followed have had an importance extending well beyond their impact on the chemotherapy of tuberculosis. ${ }^{18}{ }^{19}$ They were neither the first randomised studies nor the first using statistical analyses. They did, however, show that it was possible to undertake scientific therapeutic research in patients with lethal diseases and how the outcome could have major implications for clinical practice and public health. It is small wonder that 30 years later Cochrane, in assessing the contributions made by various specialties towards measuring their own efficiency and effectiveness, gave "first prize" to respiratory doctors. ${ }^{20}$ (He awarded the wooden spoon to obstetricians and gynaecologists for failing to evaluate rigorously their use during the 1960s and 1970s of techniques such as cervical cytology, induction, ultrasonography fetal monitoring, and tests of placental functions.)

\section{Further developments}

While Britain can thus take pride in developing the randomised controlled trial credit for introducing the double blind technique must go to the United States. The first double blind clinical trial was undertaken by Harry Gold in studies of the effects of antianginal drugs, ${ }^{21}$ though the term was not coined until 15 years later."2 The technique was successfully adopted by Beecher and his colleagues in a series of important studies of the efficacy of analgesic agents. ${ }^{23-26}$ It is now universally used in evaluating drugs whose therapeutic effects are subjective (for example, hypnotics, antidepressants, neuroleptics, and anxiolytics) or if there is a subjective element in the measurement of the response (for example, with antihypertensive drugs). Moreover, double blind methods are a common feature of trials with objective end points: they minimise selection bias and enable discrimination between adverse reactions and other adverse events.

Postwar developments in clinical trials have taken several directions. Firstly, considerable efforts have been made to develop reliable, valid methods of measuring therapeutic effects. ${ }^{27}$ These include not only adaptations of conventional measures of objective physiological and pathological changes but also the invention of specific and sensitive ways of assessing subjective drug response. Rating and visual analogue scales $^{28}$ have made very real contributions to therapeutic research. Secondly, biostatistical advances have added rigour and sophistication to clinical trial methodology. These include sequential methods,$^{29}$ the use of survival curves,,$^{30.31}$ stratification techniques,,$^{323}$ interim analyses, ${ }^{3435}$ and meta-analyses. ${ }^{36} 37$

Further important developments have been the attempts to ensure that while clinical trials remain scientifically rigorous they also have practical immediacy. Increasingly attention has been directed to the importance of erroneously concluding no difference between two treatments (type II errors) due to inadequate numbers; to the limited practical value of trials in groups of patients who are unrepresentative of the population as a whole ${ }^{38}$; and to the benefits of analysing trials by "treatment intent" rather than "treatment result." ${ }^{39}$ Clinical trialists, moreover, have been intensely critical of their own and others' work. ${ }^{00-43}$ This has undoubtedly enhanced the scientific rigour of therapeutic research. Finally, the methodology of the randomised controlled trial has been extended to other disciplines such as surgery ${ }^{+45}$ and screening. ${ }^{+6}$

\section{Trading risk for benefit}

One of the earliest demonstrations of the adverse effects of treatment and of the difficulties facing the sceptical investigator is provided by the experience of Dr P C A Louis of the Charité Hospital, Paris. During the early years of the nineteenth century, while attempting to determine the most appropriate day to bleed patients with pneumonia, ${ }^{47}$ he was forced to the conclusion that the longer "treatment" was delayed the better the outcome for the patient. He even suggested that the outcome might be improved still further if venesection was avoided altogether. His anguish survives:

The results of my experiments on the effects of bleeding in inflammatory conditions are so little in accord with common opinion that it is only with hesitation that I have decided to publish them. The first time I analysed the relevant facts, I believed that I was mistaken, and I repeated my work but the results of this new analysis remains the same ...

Over the past 150 years doctors, patients, and the public have now become much more conditioned to the possibilities of iatrogenic disease. As in other subjects in which risk-benefit ratios are assessed ${ }^{+1}$ three broad approaches have evolved. ${ }^{+9}$

Formal analysis seeks to quantify each and, by simple difference, yield a logical course of action. Large scale randomised controlled trials analysed by intention to treat are particularly appropriate for this form of risk-benefit assessment: trials of thrombolysis after acute myocardial infarction and of lipid lowering drugs in patients with hypercholesterolaemia are examples of the technique at its best. The principal weakness of formal analysis, however, is that it is difficult to apply if the risks and benefits have differen end points. How do you balance the small reduction in the incidence of stroke in patients with mild to moderate hypertension treated with $\beta$ blockers or diuretics against the much more frequent adverse effects, which may include rashes, breathlessness, impotence, and weakness? In other subjects solutions to these problems based on decision theory have been devised, but such approaches have yet to be widely accepted in medicine. ${ }^{48}$

The second method, comparative analysis, compares the toxicities of compounds with equivalent therapeutic properties. It has been done most successfully with non-steroidal anti-inflammatory drugs, antidepressants, and biguanide antidiabetic drugs. The underlying assumption of therapeutic equivalence, however, can be difficult to substantiate. Moreover the method 
may be insufficiently sensitive to changing standards. The continuing wide availability and use of butazones (phenylbutazone and oxyphenbutazone) long after less toxic non-steroidal anti-inflammatory drugs had become available is an important example.

Judgmental analysis remains the most common form of risk-benefit assessment in therapeutics. Despite its susceptibility to prejudice, bias, and personal ignorance and the difficulties it poses for medical teachers no adequate substitute has yet been found. Perhaps, in the future, doctors will become more willing to attempt to understand the language and philosophy of decision analysis.

\section{The future of rational therapeutics}

In the light of advances over the past 50 years the future of rational therapeutics should be bright. Yet attacks, many unintentional, continue to be made.

Drug regulatory authorities in developed countries have played a singular part in demanding evidence of efficacy from randomised controlled trials before giving marketing authorisation for new drugs. The European Community, for example, has published detailed guidelines covering a wide range of conditions on the type of clinical studies that new drugs should undertake. $^{50}$ It is disappointing, therefore, to see that the commission, in its draft directive outlining the arrangements for a single pharmaceuticals market in $1992,{ }^{51}$ proposes a category of "provisional authorisation." This would allow the marketing of a new drug that fails to satisfy the usual requirements of quality, safety, and efficacy if it is intended for treating a serious or life threatening disease for which no effective treatment is available. Superficially this sounds humane and was undoubtedly drafted with the best of intentions. Unfortunately it is likely, if enacted, to permit the widespread sale and supply of unproved and possibly ineffective new products. I strongly hope that the commission will heed the words of Bradford Hill written more than 50 years ago: "The time for a test of a new method of treatment is clearly in its early days when opinions on it differ, and equivalent patients, treated and untreated, are available for study." ${ }^{2}$ The issue, and Bradford Hill's principle, is as important for the evaluation of treatment in conditions such as AIDS $^{53}$ as it ever was for tuberculosis.

The research and medical departments of the international pharmaceutical industry have also contributed substantially to rational therapeutics and to clinical trial methodolgy. Though they have undoubtedly been stimulated by the demands of national drug regulatory authorities, they have often undertaken studies on established remedies as well as novel ones. The industry's marketing departments, however, have been less helpful in promoting rational therapeutics, ${ }^{545}$ and in some respects things are little better than they were at the turn of the century.

Rational therapeutics receives little help from practitioners of complementary medicine. Most of the treatments offered by such specialists are based on hypotheses that have little or no scientific basis, with virtually no confirmation from randomised clinical trials. Yet it is perfectly feasible to conduct clinical trials of treatments used in alternative medicine. ${ }^{56}$

Finally, rational therapeutics was recently attacked from a total unexpected quarter. In an editorial in Nature drug regulatory agencies in general and the American Food and Drug Administration in particular were castigated for demanding that the safety and efficacy of biotechnology products should warrant the same criteria as are expected for synthetic chemicals." The author wrote "Is the full and expensive apparatus of these enquiries necessary when the materials on trial are intended to be identical with those produced naturally in normal human beings?" The editorial went on to describe this as "the modern equivalent of the quaint British practice of sending a man with a red flag in front of the early railway locomotives." Products of biotechnology are likely to play a major therapeutic role in the future. Nature's spokesperson is obviously (and surprisingly) unaware that biotechnological products may not be identical with their physiological counterparts even when the amino acid sequence is the same and that the administration of supraphysiological doses into non-physiological body compartments and spaces may have unsuspected consequences. Remember what happened with cortisone.

The twentieth century has seen only the beginnings of rational therapeutics. If we fail to ensure that it blossoms in the twenty first century society as a whole will be the loser.

Although the opinions expressed in this essay are mine alone they have been moulded by conversations and correspondence with Sir Austin Bradford Hill, Professor J G Scadding, Professor D A Mitchison, and Dr Louis Lasagna. That these pioneers of modern experimental therapeutics should have given so generously of their time, energy, and memories is testimony to their continuing commitment to its development.

1 British Medical Association. Secret remedies: what they cost and what they contain. London: BMA, 1909

2 Anonymous. The composition of certain secret remedies XXII. Medicines for general use. Br Med 7 1909; i:544-6.

3 Select Committee on Patient Medicines. Report. London: HMSO, 1914.

4 Mann RD. Modern drug use: an enquiry on historical principles. Lancaster: MTP Press, 1984.

5 Hart PD. Chemotherapy of tuberculosis: research during the past 100 years. Br Med F 1944;ii:805-10.

6 Dawson W. The comparative pharmacology of benoxaprofen. I Rheumatol 1980;6(suppl):5-11.

7 Holy Bible. Daniel i, 3-15.

8 Lind J. A treatise of the scurvy. Edinburgh: Edinburgh University Press, 1953. (Reprinted.)

9 Lasagna L. On evaluating drug therapy: the nature of the evidence. In: Talalay $P$, ed. Drugs in our society. Baltimore: John Hopkins Press, 1963.

10 Leighton G, McKinlay PL. Milk consumption and the growth of schoolchildren. London: HMSO, 1930.

11 Student. The Lanarkshire milk experiment. Biometrika 1931;23:398-406.

12 Medical Research Council. The serum treatment of lobar pneumonia. $\mathrm{Br}$ Med $\mathrm{f}$ $1934 ; i: 241-5$.

13 Medical Research Council. Streptomycin treatment of pulmonary tuberculosis. BrMed F 1948;ii:769-82.

14 Hill AB. Principles of medical statistics: I. The aim of the statistical method. Lancet 1937;i:41-3.

15 Schatz A, Bugie E, Waksman SA. Streptomycin, a substance exhibiting antibiotic activity against gram-positive and gram-negative bacteria. Proc antibiotic activity against gram
Soc Exp Biol Med 1944;55:66-9.

16 Feldman WH, Hinshaw HC. Effects of streptomycin in experimental tuberculosis in guinea pigs: a preliminary report. Proceedings of the Mayo Clinic 1944;19:593-602.

17 Cook RE, Dunphy DL, Blake FG. Streptomycin in experimental tuberculosis: a report of its use in a one-year old infant. Yale fournal of Biological Medicine 1946;18:221-6.

8 Medical Research Council. Treatment of pulmonary tuberculosis with streptomycin and para-aminosalicylic acid. Br Med f 1950;ii: 1073-85.

19 Medical Research Council. Isoniazid in the treatment of pulmonary tuberculosis. Br Med f 1953;i:521-36.

20 Cochrane AL. 1931-1971: A critical review with particular reference to the medical profession. In: Teeling-Smith G, Wells N, eds. Medicines for the year medical profession. In: Teeling-Smith G, Wells $\mathrm{N}$, eds.

$21 \mathrm{Gold} \mathrm{H}$, Kwit NT, Out $\mathrm{H}$. The xanthines (theobromine and aminophylline) in the treatment of cardiac pain. ҰAMA 1937;108:2173-9.

22 Greiner T, Gold $\mathrm{H}$, Cattell $M$, et al. A method for the evaluation of drugs on cardiac pain in patients with angina of effort. Am $\mathcal{J}$ Med 1950;9:143-55.

23 Denton JE, Beecher HK. New analgesics I. Methods in the clinical evaluation of new analgesics. FAMA 1949;141:1051-2.

24 Denton JE, Beecher HK. New analgesics II. A clinical appraisal of the narcotic power of methadone and its isomers. JAMA 1949;141:1146-53

25 Keats AS, Beecher HK, Mosteller FC. Measurement of pathological pain in distinction to experimental pain. $\mathcal{F}$ Appl Physiol 1950;3:35-44

26 Beecher HK. Experimental pharmacology and measurement of the subjective response. Science 1952;116:157-62.

27 Chaput de Santonge DM, Vere DW. Measurement in clinical trials. $\mathrm{Br} f \mathrm{Clin}$ Pharmacol 1982;13:775-83.

28 Aitken RCB, Zealley AK. Measurement of moods. Br f Hosp Med 1970:4: 215-24.

29 Armitage P. Sequential medical trials. 2nd ed. Oxford: Blackwell, 1975.

30 Peto R. Peto J. Asymptomically efficient rank invariant test procedures. fournal of the Roval Statistical Society A 1972;135:185-98.

31 Cox DR. Regression models and life tables (with discussion). Journal of the Royal Statistical Society B 1972;34:187-220.

32 Feinstein AR. Clinical biostatistics-XIV. The purposes of prognostic stratification. Clin Pharmacol Ther 1972;13:285-97.

33 Pocock SJ. Allocation of patients to treatment in clinical trials. Biometric 1979;35:183-97. 
34 McPherson K. Statistics: the problem of examining accumulating data more than once. N Engl f Med 1979;290:501-2.

35 Pocock SJ. Interim analyses and stopping rules for clinical trials. In: Bithell JF, Gippi R, eds. Perspective in medical statistics. London: Academic Press, 1981:191-214.

36 Glass GV. Primary, secondary and meta-analysis of research. Educational Research 1976;5:3-8.

37 Sacks HS, Berrier J, Reitman D, et al. Meta-analyses of randomised controlled trials. N Engl I Med 1987;316:450-5

38 Elwood PC. Randomised controlled trials: sampling. $\mathrm{Br} f$ Clin Pharmacol 1982;13:631-6.

39 Lovell RRH. Problems of interpretation in secondary prevention trials in coronary heart disease. Med $\mathcal{F}$ A ust 1977;14:224-6.

40 Gifford RH, Feinstein AR. A critique of methodology in studies of anticoagulant therapy for acute myocardial infarction. $N$ Engl 7 Med 1969;280:351-7.

41 Fletcher RH, Fletcher SW. Clinical research in medical journals. $N$ Engl f Med 1979;301:180-3.

42 DerSimonian R, Charette LJ, McPeek B, Mosteller F. Reporting on methods in clinical trials. $N$ Engl F Med 1982;306:1332-7.

43 Lavori PW, Louis TA, Bailar JC, Polansky M. Designs for experimentsparallel comparisons of treatment. $N$ Engl F Med 1983;309:1291-9.

44 Cobb LA, Thomas GI, Dillard DH, et al. An evaluation of internal-mammaryartery ligation by a double blind technique. $N$ Engl f Med 1959;260:1115-8

45 Patchell RA, Tibba PA, Walsh RJ, et al. A randomised trial of surgery in the treatment of single metastases to the brain. $N$ Engl $\mathcal{H}$ Med 1990;322: 494-500.
46 Roberts MM, Alexander FE, Anderson TJ, et al. Edinburgh trial of screening for breast cancer: mortality at seven years. Lancet 1990;335:241-6.

.

48 Fischhoff B, Lichtenstein S, Slovic P, Derby SL, Keeney RL. Acceptable risk. Cambridge: Cambridge University Press, 1981.

49 Rawlins MD. Trading risk for benefit. In: Mann RD, ed. Risk and consent to risk in medicines. Carnforth: Parthenon, 1989:193-202.

50 Committee on Proprietary Medicinal Products. The rules governing medicinal products in the European Community. Vol III. Guidelines on the quality, safety and efficacy of medicinal products for human use. Brussels: Commission of the European Communities, 1989.

51 Commission of the European Communities. Proposal for a council directive amending directives $65 / 65 / E E C, 75 / 318 / E E C$, and 75/319/EEC. Brussels: Commission of the European Communities, 1990.

52 Hill AB. Artificial pneumothorax on statistical trial: reply. Lancet 1937;i: 535-6.

53 Broader S. Controlled trial methodology and progress in treatment of the acquired immunodeficiency syndrome (AIDS). Ann Intern Med 1989;110: 417-8.

54 Medawar C. The wrong kind of medicine. London: Consumers Association and Hodder and Stoughton, 1984.

55 Collier J. The health conspiracy. London: Century, 1989.

56 Lewitt G, Brown PK, Tyrell DA. Controlled study of the effects of a homoepathic dilution of influenza vaccine on antibody titres in man. Complementary Medical Research 1989;3:22-4.

57 Anonymous. Biotechnology eclipsed? Nature 1990;343:494.

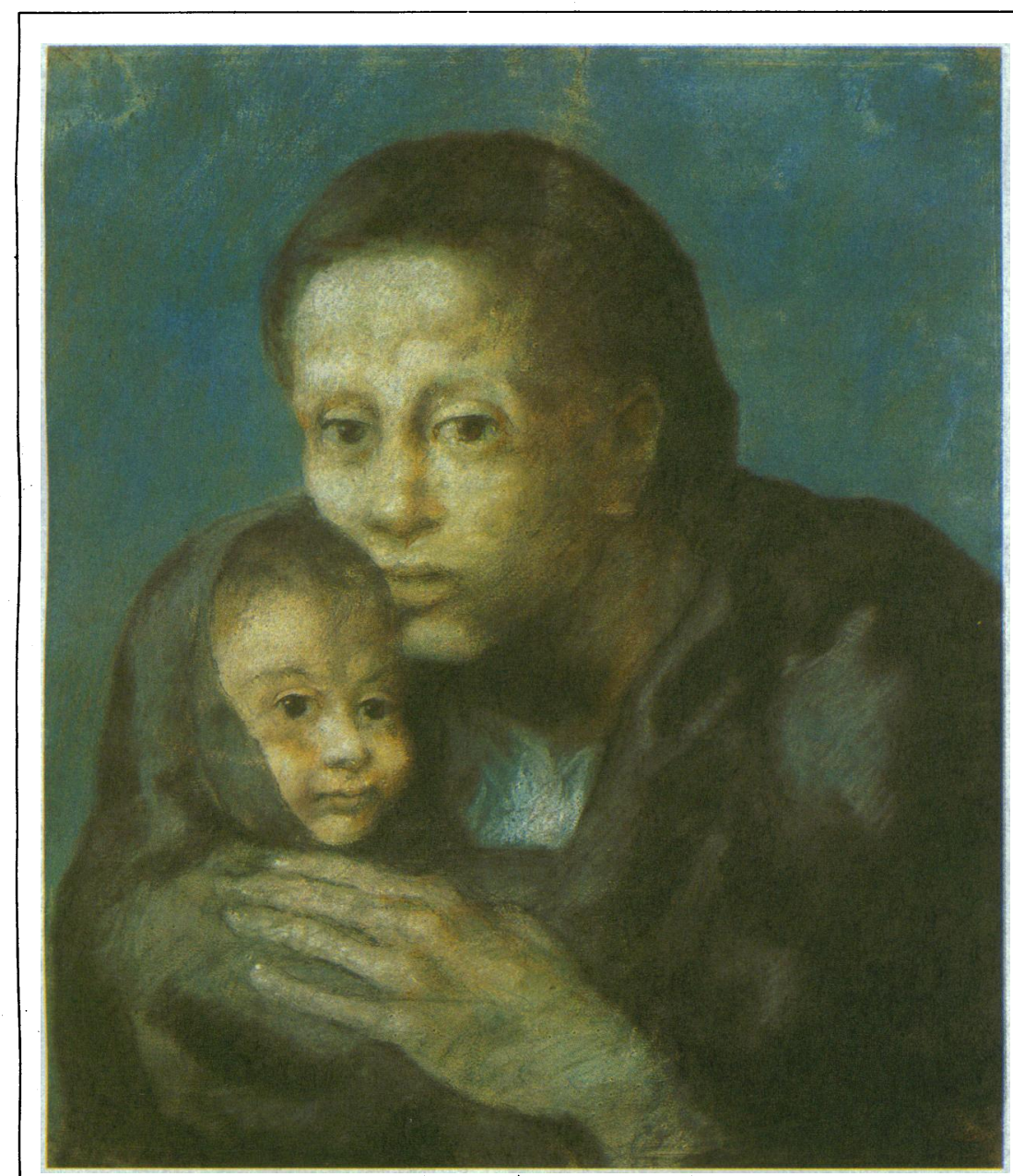

\section{The Sick Child (1903)}

\section{Pablo Picasso (1881-1973; Spanish)}

At the turn of the century Paris was the cutural centre of the avant-garde and the natural aim of any ambitious artist. Picasso arrived from Barcelona in 1900, alternating between the two cities for the next four or five years. This was a time when he was to suffer not only poverty but depression, which he translated into the works of his "blue," or classical, period. The themes of these pictures are usually poverty and despair, the subjects social outcasts.

One of the Spanish pictures of the blue period, the pastel "The Sick Child," is reminiscent of a Madonna and Child. But there the likeness ends. It is a picture of despair. The boy's face is so emaciated that his cheekbones almost protrude through the flesh and it is painful to meet his eyes. Although his mother is touchingly protective, she cannot conceal her anguish. In less sensitive hands this theme might have been sentimental, but Picasso has produced a haunting image. In particular the subtle use of blue over its entire range complements the subject and is an ideal symbol of poverty and sadness. Pastel is a notoriously difficult medium but Picasso uses it here with consummate skill. It seems extraordinary that a mere four years separate this gentle image from the aggression of "Les Demoiselles d'Avignon."

\section{CLASSIC OF THE DECADE}

1900: Sigmund Freud's Die Traumdeutung. Leipzig: F Deuticke.

\section{Rise of the British Pharmaceutical Industry}

continued from page 728

2 Liebenau J. Medical science and medical industry. The formation of the American pharmaceutical industry. Baltimore: Johns Hopkins University Press, 1987. 3 Mahoney T. The merchants of life. An account of the American pharmaceutical industry. London: Harper, 1959.

4 Liebenau J. Ethical business: the formation of the pharmaceutical industry in Britain, Germany and the United States before 1914. In: Davenport-Hines RPT, Jones G, eds. The end of insularity. Essays in comparative business history. London: Cass, 1988.

5 Liebenau J. Industrial R\&D in pharmaceutical firms in the early twentieth century. Business History 1984;26:329-46.
6 Davis W. The pharmaceutical industry. A personal study. Oxford: Pergamon, 1967.

7 Liebenau J. The British success with penicillin. Social Studies of Science 1987;17:69-86.

8 Burstall ML, Dunning JH, Lake A. Mulninational enterprises, governments and technology: pharmaceutical industry. Brussels: Organisation for Economic Cooperation and Development, 1981.

9 Burstall ML. The community's pharmaceutical industry. Brussels: European Communities Commission, 1985.

10 Silverman M, Lee PR. Pills, profits and politics. Los Angeles: University of California Press, 1974.

11 Temin P. Taking your medicine: drug regulation in the United States. Cambridge, Massachusetts: Harvard University Press, 1980.

12 Schwartzman D. Innovation in the pharmaceutical industry. Baltimore: Johns Hopkins University Press, 1976 